Título artículo / Títol article: Risk assessment for drugs of abuse in the Dutch watercycle

Autores / Autors

Revista:

Versión / Versió:

Cita bibliográfica / Cita bibliogràfica (ISO 690): van der Aa, Monique ; Bijlsma, Lubertus ; Emke, Erik ; Dijkman, Ellen ; van Nuijs, Alexander L.N. ; van de Ven, Bianca ; Hernández Hernández, Félix Javier ; Versteegh, Hans ; Voogt, Pim de

Water Research Volume 47, Issue 5, April 2013
Preprint de l'autor

VAN DER AA, Monique, et al. Risk assessment for drugs of abuse in the Dutch watercycle. Water research, 2013, 47.5: 1848-1857. 


\section{Risk assessment for drugs of abuse in the Dutch watercycle}

2 Monique van der Aa ${ }^{a^{*}}$, Lubertus Bijlsma ${ }^{\mathrm{b} \S}$, Erik Emke ${ }^{\mathrm{c}}$, Ellen Dijkman ${ }^{\mathrm{a}}$, Alexander L.N. van

3 Nuijs $^{\mathrm{d}}$, Bianca van de Ven ${ }^{\mathrm{a}}$, Felix Hernández ${ }^{\mathrm{b}}$, Ans Versteegh ${ }^{\mathrm{a}}$, Pim de Voogt ${ }^{\mathrm{c}, \mathrm{e}}$

4

$5{ }^{a}$ National Institute for Public Health and the Environment RIVM, Postbus 1, 3720 BA.

6 Bilthoven, the Netherlands.

$7 \quad{ }^{b}$ Research Institute for Pesticides and Water, University Jaume I, Avda. Sos Baynat, E-12071

$8 \quad$ Castellón, Spain.

$9{ }^{c}$ KWR Watercycle Research Institute, Chemical Water Quality and Health, P.O. Box 1072,

103430 BB Nieuwegein, the Netherlands.

$11{ }^{\mathrm{d}}$ University of Antwerp, Toxicological Centre, Universiteitsplein 1, 2610 Antwerp, Belgium.

12 e Institute for Biodiversity and Ecosystem Dynamics, University of Amsterdam, P.O. Box 1394248,1090 GE Amsterdam, the Netherlands.

$14 \oint$ Visiting scientist at RIVM

15

$16 *$ Corresponding author

17 


\section{ABSTRACT}

A screening campaign of drugs of abuse (DOA) and their relevant metabolites in the aqueous environment was performed in the Netherlands. The presence of DOA, together with the potential risks for the environment and the possible human exposure to these compounds through consumption of drinking water was investigated. Sewage water (influent and effluent), surface water of the rivers Rhine and Meuse, and drinking water (raw and finished) were analysed by four different laboratories using fully in-house validated methods for a total number of 34 DOA and metabolites. In this way, data reported for several compounds could also be confirmed by other laboratories, giving extra confidence to the results obtained in this study. 17 and 22 DOA were detected and quantified in influent and effluent sewage samples, respectively. The tranquilizers oxazepam and temazepam, and cocaine and its metabolite benzoylecgonine were found in high concentrations in sewage water. Nine compounds were possibly not efficiently removed during treatment and were detected in surface waters. The results indicated that substantial fractions of the total load of DOA and metabolites in the rivers Rhine and Meuse enter the Netherlands from abroad. For some compounds, loads appear to increase going downstream, which is caused by a contribution from Dutch sewage water effluents. As far as data are available, no environmental effects are expected of the measured DOA in surface waters.

In raw water, three DOA were detected, whereas in only one finished drinking water out of the 17 tested, benzoylecgonine was identified, albeit at a concentration below the limit of quantification $(<1 \mathrm{ng} / \mathrm{L})$. Concentrations were well below the general signal value of 1 $\mu \mathrm{g} / \mathrm{L}$, which is specified for organic compounds of anthropogenic origin in the Dutch Drinking Water Act.

\section{Keywords}


43 Drugs of abuse, sewage water, surface water, drinking water, environmental risk 44 characterization 


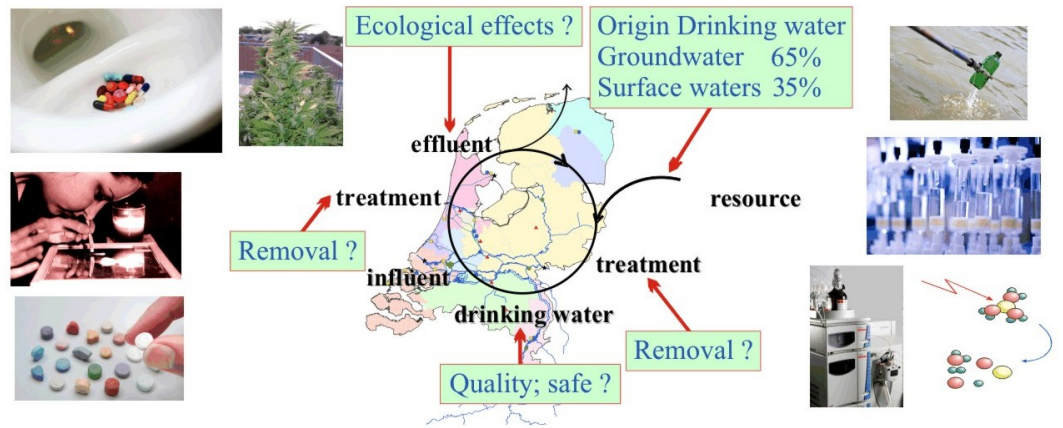




\section{Introduction}

Drugs of abuse (DOA) and their metabolites have recently been recognised as a novel group of environmental contaminants (Zuccato et al., 2008a). Owing to the increased sensitivity of analytical methods and the high level of world-wide consumption of DOA, they are among the growing number of emerging compounds that are detected at trace concentrations in the aqueous environment, including sewage water and surface waters.

DOA refers to both illegal drugs and misused prescription drugs, such as tranquilizers. They have received special attention recently since a novel approach allowed to study DOA consumption patterns of a population through sewage water analysis (Daughton, 2001; Zuccato et al., 2008b; van Nuijs et al., 2010; Thomas et al., 2012). Following consumption and excretion, some DOA and their metabolites are continuously released into the aquatic environment due to their insufficient elimination in sewage treatment plants (STPs) (HuertaFontela et al., 2008; Kasprzyk-Hordern et al., 2009; van Nuijs et al., 2009a; Postigo et al., 2010). Recent studies have shown the presence of DOA and their metabolites in STP effluents and river water in Australia (Irvine et al., 2011), Europe (Boleda et al., 2009; van Nuijs et al., 2009a; Postigo et al., 2010; Baker and Kasprzyk-Hordern, 2011; Hernandez et al., 2011) and North America (Jones-Lepp et al., 2004; Bartelt-Hunt et al., 2009).

Although the reported concentrations in surface waters are in general low, possible toxicological effects on animals, plants and humans may occur as a result of their presence in the aquatic environment. Especially, long-term effects on organisms and the effects of combined exposure to multiple compounds are of potential concern. However, so far, little ecotoxicological information for DOA is available and a well-founded scientific risk assessment is not yet possible. Although some information is available on DOA removal and transformation products formed during (drinking) water treatment processes (Huerta-Fontela et al., 2008), much more research is required for a better knowledge and understanding of 
these processes. In the Netherlands, where approximately $40 \%$ of the drinking water is produced from surface water, little is known about the occurrence of DOA and their metabolites in the Dutch water cycle. Exploratory studies conducted in the period 2007-2010 have revealed the presence of benzoylecgonine, methadone, codeine and three tranquilizers (nordazepam, temazepam and oxazepam) in Dutch surface waters and sewage effluents (de Voogt et al., 2011; Hogenboom et al., 2009). The results from this study implied a clear need for a more detailed monitoring campaign in the Netherlands.

This work presents the results of a large monitoring exercise on the occurrence of DOA and metabolites in the Dutch watercycle. To the best of our knowledge, this study is one of the largest of this kind in Europe, both in terms of number of analytes investigated and types of water studied. In addition, samples were individually analysed by four different laboratories, using their own validated analytical methodology. Five DOA were determined by all four laboratories and additional seven by at least two laboratories. The fact that three DOA (amphetamine, MDMA and benzoylecgonine) were found in several water samples by all laboratories allowed the performance of an interlaboratory exercise.

Beforehand, a selection of compounds was made, applying the following criteria: the results of the aforementioned preliminary inventory studies; international occurrence data on DOA and metabolites in the aqueous environment (Baker and Kasprzyk-Hordern, 2011; Bartelt-Hunt et al., 2009; Boleda et al., 2009; Hernandez et al., 2011; Irvine et al., 2011; Jones-Lepp et al., 2004; Postigo et al., 2010; van Nuijs et al., 2009a); the estimated DOA consumption in the Netherlands, which was based on criteria such as (il)legal import volumes and anonymous surveys (van Laar et al., 2007), the availability of reference standards and internal isotope-labelled standards, and the scope of the methods applied by the different laboratories participating. 
96 DOA and metabolites in the Dutch watercycle (sewage influents and effluents, surface water

97 and drinking water); (2) to perform an ecotoxicological risk assessment of the levels of DOA 98 observed in surface waters.

99 


\section{Methods and materials}

101

\subsection{Sampling sites and sample collection}

103

The sampling campaign in this study was performed by the Dutch National Institute

104 for Public Health and the Environment (RIVM). All water samples were analysed by three

105 laboratories: RIVM, KWR Watercycle Research Institute and University Jaume I (UJI). In

106 addition, sewage water samples from four STPs (Utrecht, Apeldoorn, Amsterdam,

107 Eindhoven) were also analysed by the University of Antwerp (UA).

108

109

Figure S1 of the Supplementary Information (SI) presents an overview of the sampling locations. Samples were collected from 65 sites and corresponded to three different types of water:

(1) Surface water: samples were collected at all nine surface water intake points for drinking water production in the Netherlands. Eight of these locations were part of the Meuse and Rhine river basins, and one was part of the Ems river basin. In addition, samples were taken at five locations along the rivers Rhine and Meuse.

(2) Raw water and finished drinking water: samples were taken at ten production sites where drinking water is produced from surface water and another seven drinking water production sites where drinking water is produced from river bank filtration. Raw water refers to the source water that enters the drinking water production facility. At some production sites

120 this raw water has undergone pre-treatment, e.g., direct filtration, subsoil passage in the dune 121 areas or storage in a reservoir, before it enters the drinking water treatment plant. Finished 122 drinking water refers to water that is distributed as tap water. Drinking water treatment mostly 123 consists of a combination of coagulation/flocculation and filtration/flotation, $\mathrm{UV} / \mathrm{H}_{2} \mathrm{O}_{2}$ 124 treatment or ozonation followed by activated carbon filtration. 
(3) Sewage water: influent and effluent water samples were collected from eight STPs. The size of these conventional biological treatment facilities varies from 37,000 to 1 million equivalent-inhabitants.

Samples were collected in 2009 between October 4th and November 1st. At each sampling location for surface and drinking water, grab samples were taken. At the drinking water production sites, both raw water and finished drinking water were sampled on the same day, without accounting for lag-time. At the STPs, 24-hour flow dependent samples from influent and effluent were collected on the same weekend day, without accounting for lagtime within the STP. All samples were collected in amber glass bottles, and transported and stored in the dark at $4{ }^{\circ} \mathrm{C}$.

\subsection{Selection of analytes}

A total of 34 DOA and metabolites belonging to 6 different chemical classes were selected. The list of compounds, and isotopically labelled internal standards (ILIS) used for matrix effects correction and quantification, by the four participating laboratories, and details on preparation and storage of standard solutions are given in SI and Table S1.

\subsection{Analytical methods}

Table 1 presents an overview of the main characteristics of the analytical methods used by the four laboratories that participated in this study.

Sample clean-up and preconcentration was achieved by off-line solid-phase extraction (SPE). Analyses of the final sample extracts were performed by liquid chromatography coupled to tandem mass spectrometry (LC-MS/MS). All instruments employed electrospray ionization (ESI) operating in positive mode. The applied mass spectrometric techniques were 
150 triple quadrupole mass analyzers (QqQ), except for KWR that used high-resolution mass 151 spectrometry (LTQ FT Orbitrap). Further details on the analytical procedures and instrument 152 parameters can be found elsewhere (UJI (Bijlsma et al., 2009), KWR (de Voogt et al., 2011), 153 UA (van Nuijs et al., 2009b)), except for RIVM which is described in Supplementary 154 Information.

\subsection{Quality assurance}

The analytical methods used in the present study were validated in terms of linearity,

158 limit of detection (LOD), limit of quantification (LOQ), accuracy and precision (de Voogt et 159 al., 2011; Bijlsma et al., 2009; van Nuijs et al., 2009b). ILIS were used to compensate for 160 matrix effects (Hernández, 2005; Vanderford and Snyder, 2006). The identity of each of the 161 investigated analytes in samples of wastewater, surface water and drinking water was confirmed by fulfilling relative retention time criteria and mass spectrometric identification criteria (Commission Decision 2002/657/EC). An overview of the LOQs of the different

164 methods applied can be found in Table S2.

\subsection{Environmental risk characterization}

Environmental risk characterization for substances is usually performed by calculating a Risk Characterization Ratio (RCR), which is a PEC/PNEC or MEC/PNEC ratio, in which PNEC (Predicted No Effect Concentration) is an estimate for the highest concentration of

170 substance not affecting aquatic ecosystems, and PEC or MEC is the Predicted or Measured

171 Environmental Concentration in the aquatic environment. If the $\mathrm{RCR}$ is $<1$, no potential risk

172 to the aquatic environment is expected. A literature search was carried out to obtain PNECs

173 for the DOA detected in surface waters. In 2007, the Norwegian Pollution Control Authority

174 collected PNECs of pharmaceuticals, narcotics, and personal care products. For compounds 
175 where no effect data were available, they used Quantitative Structure-Activity Relationship

176 (QSAR) or Ecological Structure Activity Relationships (ECOSAR) models to estimate the

177 potential effects of each compound (PNECECOSAR) (Grung et al., 2007).

178

\section{RESULTS AND DISCUSSION}

180

\subsection{Comparative analysis between laboratories}

As mentioned above, all water samples were analysed by three laboratories: RIVM,

KWR and UJI. Some of the STP wastewater samples were also analysed by the UA. To the best of our knowledge, this study is unique with respect to the number of different laboratories and methodologies involved in analysing the same water samples. From the total of $34 \mathrm{DOA}$ and metabolites that were analysed in this monitoring campaign, 12 compounds were analysed by two or more laboratories. Three of these DOA (amphetamine, MDMA, and benzoylecgonine) were detected in sewage water by all four laboratories. This allowed us to perform an extra validation of the methodology applied, a relevant aspect taking into account the analytical difficulties associated with these complex sample matrices. So, in addition to

191 the criteria applied by each laboratory to assure quality, the deviations between the results reported by the participants were used to prove the reliability of the analytical methods 193 applied.

Table S3 shows comparative data obtained for the analysis of these three DOA in ten

195 sewage waters (analysed by four laboratories) and six surface waters (analysed by three

196 laboratories). Relative standard deviations (RSD) and overall average concentrations for the

19716 samples analyzed are shown in the Supplementary Information. In general, the overall

198 (among laboratories) RSD was between 7 and 26\%, with the exception of the RSD for 199 benzoylecgonine in two STP effluent samples $(\mathrm{RSD}=38 \%)$. The fact that samples were 
analyzed using different methodologies and that reported concentrations were comparable, renders high confidence to the results obtained.

\subsection{Drugs of abuse and metabolites in the Dutch water cycle}

An overview of the monitoring results of DOA in the Dutch water cycle is presented

in Table 2. The average \pm standard deviation (SD), range and median of the quantified levels illustrate the dispersion and variation of the obtained results. Out of the total number of 34 DOA and metabolites analysed, 24 compounds were detected and quantified in sewage water,

9 in surface water, 3 in raw and none in finished drinking water. The presence of benzoylecgonine was confirmed in one finished drinking water sample, but at a concentration

210 below the LOQ for this analyte ( $1 \mathrm{ng} / \mathrm{L})$. It must be considered that only a single, $24-\mathrm{h}$ 211 composite sample from the effluents was collected to estimate loads of DOA discharged from 212 the STP, and that these samples were collected during the weekend. It is well-known that 213 concentrations of some DOA are higher during the weekend compared to weekdays (Thomas 214 et al., 2012). So the average loads might be different from the loads calculated in this paper. 215 Therefore, this might be seen as the worst-case scenario because of the higher concentrations 216 found in sewage water. Similarly, loads of DOA into the rivers were calculated using only a 217 single grab sample per location, which is a limitation when comparing the loads from 218 different locations and countries. However, the data presented in this work provides a 219 valuable indication of the importance of STP discharges of DOA into the environment. The 220 daily and seasonal variations of discharge loads were not an objective of the present study and 221 should be evaluated in a new set of experiments. 
In STP influents, 17 compounds could be quantified, while for effluents 22 compounds showed concentrations $>$ LOQ (Table 2). The compounds found in the STP influents were also detected in the STP effluents, except for THC-COOH and cocaethylene, whereas MDA, diazepam, nordazepam, fentanyl, ketamine, methcathinone and ritalin were solely found in effluents. Deconjugation within the STP, transformation of compounds (e.g. in the case of benzodiazepines), the higher LOQs in influent samples compared with effluents, or a combination of these processes might explain the exclusive presence and/or higher concentrations found in effluent compared to influent samples (Bones et al., 2007; Kvanli et al., 2008). To define which process occurs for which compound is beyond the scope of this study and should be a focus of completely new experiments. Moreover, conclusions about 234 removal efficiencies of the STPs cannot be drawn based on this research, since STP influents and effluents were collected on the same day and as a result lag-times were not taken into account. In a later study, removal efficiencies and daily variations were investigated in an extensive one week monitoring of 24 DOA and metabolites in Dutch influent and effluent sewage water (Bijlsma et al., 2012). Occurrence of DOA monitored by both studies is in a

239 good agreement. From the 18 common compounds included in both studies, 14 compounds 240 were detected in influents and/or effluents in both cases. The only exceptions were MDA, 241 diazepam, morphine and fentanyl that were not found in any sewage water sample analyzed 242 by Bijlsma et al. (2012). In addition, nordazepam, ketamine and ritalin were mainly found in 243 effluents, which is in correspondence with the results of the present work. A preliminary 244 conclusion that can be drawn from the present study is that 22 out of 34 DOA were not 245 completely removed during sewage water treatment. As a consequence, substantial loads of DOA and metabolites may enter receiving surface waters through STP effluents.

Figure 1 shows the calculated loads of DOA discharged from the eight Dutch STP 248 effluents collected during a weekend day. The Amsterdam STP shows highest loads towards 
surface water, up to $105 \mathrm{~g}$ /day of oxazepam. This can be related to the highest Inhabitant

250 Equivalent (I.E.) for this STP, and also to the higher consumption of DOA that is expected in 251 more urbanized areas or large cities (van Nuijs et al., 2009a; Banta-Green et al., 2009). Hence, 252 if removal efficiencies (\%) are of the same order of magnitude for all STPs, higher discharges 253 can be expected when higher I.E.s are involved. However there are some exceptions, 254 indicating that other factors also play a role (e.g. consumption of certain DOA can be 255 regionally and temporally dependent). A noticeable discharge is shown for MDMA in 256 Amsterdam (up to $80 \mathrm{~g} /$ day, 10 fold more than any of the other STPs). An estimation of the 257 discharges expressed per inhabitant also indicated highest loads of MDMA for Amsterdam 258 (data not shown). In general, discharge values of DOA expressed per inhabitant correspond 259 when comparing the different cities. A possible explanation for the relative high MDMA 260 loads in Amsterdam could be the presence of an extensive club scene in this STP region. This 261 can be linked with a higher consumption of this 'party' drug. It is noteworthy that on the day 262 before sampling, a big Halloween dance party was celebrated. Due to the travel distance of 263 the sewer and the lag-time of the STP (24 h), sampling of the influent and effluent started 264 when the main discharge of this party was already under treatment in the STP. In the same 265 line, Bijlsma et al. (2009) reported high drug levels in sewage water samples due to a special 266 music event, and suggested that these high drug levels led to a decrease in the removal 267 efficiency.

\subsubsection{Occurrence in surface waters}

In the surface waters of the rivers Rhine and Meuse, 9 DOA were detected (Table 2).

271 Oxazepam, temazepam and benzoylecgonine were most abundantly present (in $>70 \%$ of the 272 sampling locations) and concentrations were highest for the benzodiazepines, with a 273 maximum value of $68 \mathrm{ng} / \mathrm{L}$ for oxazepam. These findings are consistent with relatively high 
274 levels of benzodiazepines observed in influents and the relatively poor removal rate in Dutch 275 STPs (Bijlsma et al., 2012). Oxazepam and temazepam were among the top 10 most 276 prescribed pharmaceuticals in the Netherlands in 2008 (SFK, 2008). Other widely used 277 pharmaceuticals, such as various antibiotics, beta-blockers, lipid regulators or anti278 inflammatory pharmaceuticals were reported in comparable concentrations in the river Rhine 279 (ter Laak et al., 2010). In general, the levels of DOA and metabolites found in the river Meuse 280 were higher than those of the river Rhine, as shown in Figure 2, most probably as a result of 281 the larger dilution in the river Rhine which has a much larger flow rate than the river Meuse. 282 Based on our data, loads of DOA and metabolites through the Rhine and Meuse rivers can be 283 estimated. However it is worth mentioning that such estimations should be interpreted as 284 indicative since they are based on grab samples and on a single sampling date.

285 The loads of DOA and metabolites transported by rivers are calculated by multiplying 286 the concentrations $(\mathrm{ng} / \mathrm{L})$ with the flow rate (L/day) recorded at the sample location on the 287 sampling date. Flow rates on the sampling dates were obtained from the Dutch Ministry of 288 Waterworks database. Higher flow rates in the river Rhine led to higher estimated loads in 289 this stream (Figure 3 and Table S4). Loads were also calculated at two locations 290 downstream: Keizersveer (river Meuse) and Maassluis (river Rhine). As shown in Figure 3 291 and Tables S4 and S5, the loads generally increased downstream for the four compounds 292 presented. An increase of the riverine loads during passage of the rivers Rhine and Meuse 293 through the Netherlands is plausible, because oxazepam, temazepam and codeine are 294 consumed in the Netherlands in quantities of approximately $200-1500 \mathrm{~kg}$ per year, according 295 to sales data from the Foundation for Pharmaceutical Statistics in the Netherlands (SFK, 296 2008). Table S4 shows that for the river Rhine, the increase in loads downstream along the 297 Dutch part of the river is of the same order of magnitude as the contribution from abroad for 298 temazepam and oxazepam, whereas for benzoylecgonine and codeine the contribution from 
abroad is larger. For the river Meuse, the increase in loads for temazepam and oxazepam

300 downstream along the Dutch part of the river seems higher than the contribution from abroad

301 (Table S5). However, for the river Meuse there may also be a contribution from Belgian and

302 German tributaries that discharge their waters into the river Meuse downstream from Eijsden.

303 For benzoylecgonine and codeine loads are even decreasing downstream along the Dutch part

304 of the river, which cannot be explained. Although these calculations are only indicative with

305 considerable uncertainties, they imply that, when mitigation measures like for example

306 improved sewage treatment are considered, these should be implemented both in Dutch and in

307 Belgian / German STPs in order to effectively lower concentrations of DOA in Rhine and

308 Meuse rivers. However, more data is needed to draw definite conclusions on this matter.

309 An attempt was made to compare the increase in loads downstream along the Dutch

310 part of the rivers Rhine and Meuse with the loads from Dutch inhabitants in the Rhine and

311 Meuse catchment. Bijlsma et al (2012) showed that considerable levels of these compounds

312 can reach the Dutch surface waters through STP effluent discharges since they are not

313 efficiently removed in STPs. This potential contribution from Dutch inhabitants was

314 estimated based on the average DOA loads from the 8 STPs per I.E. discharged to surface

315 water, multiplied with the total amount of Dutch inhabitants in Rhine (ICBR, 2009) and

316 Meuse (IMC, 2008) catchments, respectively. The calculated loads are shown in Table S4

317 and Table S5. The increase in loads at the downstream stations Keizersveer (Meuse) and

318 Maassluis (Rhine) should be comparable to the estimated loads from the Dutch STPs if

319 degradation in the environment would not occur. Table S4 and Table S5 however show that

320 the loads from STPs are about an order of magnitude larger than the increase in loads at the

321 downstream stations. This means that, despite the high insecurity of the calculations which is

322 shown by the high standard deviations, also degradation in the environment might play a role. 


\subsubsection{Occurrence in the drinking water production chain}

Figure 4 presents average concentrations of DOA and metabolites observed during several stages of the drinking water production chain. Samples (from water intake locations, raw water and finished drinking water) were collected from three types of production processes where drinking water is prepared from surface waters (direct treatment and with soil aquifer recharge), and from bank filtrate. It has to be stressed here that the monitoring results are not entirely suitable to evaluate the effectiveness of the different treatment steps, since both the raw waters and finished drinking waters were sampled only once, on the same day and without accounting for lag-times. The results should therefore be regarded as indicative, and are used here merely to provide a visualisation and qualitative assessment of compounds that are not removed completely during drinking water treatment.

As shown in Figure 4, amphetamine-type stimulants, cocaine and its metabolites, benzodiazepines and opiates are present in river water at the water intake locations. However, in raw water only oxazepam, temazepam and benzoylecgonine were found, and at lower concentrations. Apparently, these compounds are removed to some extent during the treatment of raw water which includes direct filtration, subsoil passage in the dune areas or storage in a reservoir. It takes place before the water enters the drinking water treatment plant where further, more advanced treatment processes are used. Oxazepam and temazepam were not detected in the raw water that is produced from bank filtrate: possibly they were removed during bank filtration.

The treatment to produce finished drinking water mostly consists of a combination of coagulation/flocculation and filtration/flotation, $\mathrm{UV} / \mathrm{H}_{2} \mathrm{O}_{2}$ treatment or ozonation followed by activated carbon filtration. It seemed effective in the removal of the compounds selected as none of the DOAs investigated was detected, with the exception of benzoylecgonine that was confirmed at a level between LOD and LOQ $(<1 \mathrm{ng} / \mathrm{L})$ in a single finished drinking water. 
Although in our study no DOA were detected in finished drinking water, Huerta-Fontela et al.

350 (2008) did detect benzoylecgonine in Spanish drinking water. In their study on the removal

351 efficiency of Spanish drinking water treatment plants, they concluded that benzoylecgonine

352 was still detected in most finished drinking waters at mean concentrations of $45 \mathrm{ng} / \mathrm{L}$, even

353 though reductions of $90 \%$ were obtained during treatment which consists of prechlorination,

354 flocculation and sand filtration steps. Probably the use of rather advanced drinking water 355 treatment techniques in the Netherlands, like UV or ozonation, followed by activated carbon 356 filtration is more effective in reducing DOA.

\subsection{Environmental risk characterization}

The environmental risk characterization ratios were calculated by dividing the maximum concentrations measured in surface water (MEC) by the reported PNEC or PNEC $_{\text {ECOSAR. }}$

For oxazepam a PNEC was reported, and for codeine, cocaine, morphine, MDMA and methamphetamine QSAR derived PNEC $\mathrm{ECOSAR}_{\mathrm{R}}$ were available (Grung et al., 2007). For

364 temazepam and benzoylecgonine, no PNECs could be found in public literature. For 365 temazepam however, conforming to what was done for diazepam by Grung et al. (2007), the 366 PNEC for oxazepam was used as the default PNEC, as temazepam is also a benzodiazepine, 367 having a similar metabolic pathway as diazepam. For benzoylecgonine, the PNEC for cocaine 368 was used. Animal studies showed that benzoylecgonine is less toxic than cocaine, so the 369 PNEC for cocaine will be safe for benzoylecgonine as well. For methadone no PNECs could 370 be found or derived.

Table 3 shows the calculated MEC/PNEC ratios, which are well below 1 (range: 3720.0002 to 0.38 ), meaning that, as far as data are available, no environmental effects are 373 expected of the measured individual DOA in the surface water. However, most PNECs are 
374 derived by ECOSAR modelling and it is questionable if this is the most appropriate model.

375 ECOSAR modelling provides acute PNECECOSAR data but with a very high degree of

376 uncertainty. The question is whether traditional approaches to extrapolating chronic PNECs

377 are at all relevant when considering narcotic substances. The acute/chronic ratio approach

378 which was applied is founded on the toxic mechanism of non-specific narcosis, which is by

379 definition not applicable to narcotics, which have a very specific effect. A high degree of

380 uncertainty is therefore associated with the modelled acute PNEC and any assumptions made

381 in terms of extrapolating chronic PNEC data (Grung et. al. 2007). Unfortunately, no published 382 aquatic ecotoxicological data for narcotic substances are available.

\subsection{Toxicological relevance for human health through drinking water}

In one finished drinking water sample benzoylecgonine was detected, but at a concentration below the LOQ for this analyte $(1 \mathrm{ng} / \mathrm{L})$. Detection of this cocaine metabolite has also been reported in Spanish drinking water although at higher concentrations, with a mean value of $45 \mathrm{ng} / \mathrm{L}$ (Huerts-Fontela et al. 2008). No other DOA were found to be present in finished water, therefore no human health risks are expected.

Currently, for individual DOA no statutory drinking water guideline values are 391 available from e.g. European Commission, US Environmental Protection Agency (EPA) or 392 World Health Organization (WHO). According to the Dutch Drinking Water Act a general 393 signal value of $1 \mu \mathrm{g} / \mathrm{L}$ applies to organic compounds of anthropogenic origin for which no 394 individual statutory drinking water guidelines are specified. For the twelve DOA that were 395 detected in surface water and the five DOA that were detected in raw (process) water, the 396 concentrations were well below this signal value. Although more research and data are 397 needed, the results from this study suggest that the presence of DOA in drinking water should 398 not be a cause of significant concern for human health. 


\section{CONCLUSIONS}

This extensive screening campaign confirms the presence of DOA and metabolites at

402 low concentration levels in the Dutch water cycle. All samples were analysed by at least three 403 laboratories using different methodologies, a relevant and unique aspect in this type of work. 404 DOA and metabolites were detected and quantified in sewage water influents (17) and 405 effluents (22), surface water (9), and raw water (3). In finished drinking water only 406 benzoylecgonine was detected in one sample, but at a concentration below the LOQ for this 407 analyte $(1 \mathrm{ng} / \mathrm{L})$. No other DOA were found to be present in finished drinking water; therefore 408 no human health risks are expected. Concentrations of DOA observed in surface water and 409 raw water are well below the general signal value of $1 \mu \mathrm{g} / \mathrm{L}$, which is specified for organic 410 compounds of anthropogenic origin in the Dutch Drinking Water Act. For DOA for which an 411 evaluation could be made, no environmental effects are expected of the measured 412 concentrations in surface water. However further research with respect to possible long-term 413 (chronic) effects on organisms and possible effects of combined exposure to multiple 414 compounds at low concentrations is recommended, and the development of analytical 415 techniques to detect possible new emerging DOA needs further attention. 
This research received financial support from Inspectorate of the Dutch ministry of

419 Infrastructure and the Environment and the Joint Research Programme (BTO) of the Dutch 420 water companies. The authors thank the employees of the Dutch drinking water companies 421 and the sewage water treatment plants who supported our monitoring campaign. Lubertus 422 Bijlsma is very grateful to the RIVM for allowing him to perform an internship as visiting 423 scientist. AvN acknowledges the FWO (Research Foundation Flanders) for financial support. 424 Peter van Vlaardingen from RIVM is thanked for providing help on the environmental risk 425 characterization.

\section{SUPPLEMENTARY INFORMATION}

In this section, useful information on the chemical and materials and the analytical procedure used by RIVM are given. Additionally, an overview of the sampling locations is 430 given (Figure S1). Furthermore five tables are added: Table S1 provides the list of DOA 431 investigated by the four participating laboratories, Table S2 shows an overview of the LOQs 432 (ng/L) per compound, sample matrix and laboratory, Table S3 shows a comparison of results 433 obtained by different laboratories, Table S4 compares the estimated loads entering the river 434 Rhine through German STPs and through Dutch STPs, and Table S5 compares the estimated 435 loads entering the river Meuse through Belgian STPs and through Dutch STPs. 


\section{REFERENCES}

438 Baker, D.R., Kasprzyk-Hordern, B., 2011, Multi-residue analysis of drugs of abuse in wastewater and surface water by solid-phase extraction and liquid chromatographypositive electrospray ionization tandem mass spectrometry. J. Chromatogr. A 1218, 1620 $-1631$.

Banta-Green, C., Field, J., Chiaia, A.C., Sudakin, D.L., Power, L., De Montigny, L., 2009, The spatial epidemiology of cocaine, methamphetamine and 3,4-methylenedioxymethamphetamine (MDMA) use: a demonstration using a population measure of community

Bartelt-Hunt, S.L., Snow, D.D., Damon, T., Shockley, J., Hoagland, K., 2009, The occurrence of illicit and therapeutic pharmaceuticals in wastewater effluent and surface waters in Nebraska. Environ. Pollut. 157, 786 - 791.

Bijlsma, L., Sancho, J.V., Pitarch, E., Ibáñez, M., Hernández, F., 2009, Simultaneous ultra -high-pressure liquid chromatography-tandem mass spectrometry determination of amphetamine and amphetamine like stimulants, cocaine and its metabolites, and a cannabis metabolite in surface water and urban wastewater, J. Chromatogr. A 1216, 3078 $-3089$.

Bijlsma, L., Emke, E., Hernández, F., de Voogt, P., 2012, Investigation of drugs of abuse and relevant metabolites in Dutch sewage water by liquid chromatography coupled to high resolution mass spectrometry. Chemosphere, 89, 1399 - 1406.

Boleda, M.R., Galceran, M.T., Ventura, F., 2009, Monitoring of opiates, cannabinoids and their metabolites in wastewater, surface water and finished water in Catalonia, Spain. Water Res. 43, 1126 - 1136. 
460 Bones, J., Thomas, K.V., Paul, B., 2007, Using environmental analytical data to estimate 461 levels of community consumption of illicit drugs and abused pharmaceuticals. J. Environ. Monit. 9, $701-707$.

463 Commission Decision 2002/657/EC of 12 August implementing Council Directive 96/23/EC 464 concerning performance of analytical methods and the interpretation of results. Off. $J$. $465 \quad$ Eur. Commun., 2002, L221/8.

466 Daughton, C.G., 2001. In: Daughton, C.G., Jones-Lepp, T.L. (Eds.). Pharmaceuticals and 467 personal care products in the environment, scientific and regulatory issues, American

De Voogt, P., Emke, E., Helmus, R., Panteliadis, P., Van Leerdam, J.A., 2011, Determination of illicit drugs in the watercycle by LC-orbitrap MS. In Castiglioni S, Zuccato E, (Eds.) Mass Spectrometric Analysis of Illicit Drugs in the Environment. Wiley, New York, pp. 85 - 114.

Grung, M., Heimstad, E.S., Moe, M., Schlabach, M., Svenson, M., Thomas, K., Woldegiorgis, A., 2007, Human And Veterinary Pharmaceuticals, Narcotics, And Personal Care Products In The Environment. Statens forurensningstilsyn, Report

Hernández, F., Bijlsma, L., Sancho, J.V., Díaz, R., Ibáñez, M., 2011, Rapid wide-scope screening of drugs of abuse, prescription drugs with potential for abuse and their metabolites in influent and effluent urban wastewater by ultrahigh pressure liquid chromatography-quadrupole-time-of-flight-mass spectrometry. Anal. Chim. Acta 684, 96 $-106$. 
Hernández, F., Sancho, J.V., Pozo, O.J., 2005, Critical review of the application of liquid chromatography/ mass spectrometry to the determination of pesticide residues in biological samples. Anal. Bioanal. Chem. 382, 934 - 946.

Hogenboom, A.C., Van Leerdam, J.A., de Voogt, P., 2009, Accurate mass screening and identification of emerging contaminants in environmental samples by liquid chromatography-LTQ FT Orbitrap mass spectrometry. J. Chromatogr. A 1216, 510 519.

Huerta-Fontela, M., Galceran, M.T., Ventura, F., 2008, Stimulatory drugs of abuse in surface waters and their removal in a conventional drinking water treatment plant. Environ. Sci. Technol. 42, $6809-6816$.

ICBR, 2009, Internationally Coordinated Management Plan for the International River Basin District of the Rhine. ICBR report, the Netherlands

IMC, 2008, Meuse part A. Ontwerp van het overkoepelend deel van het beheersplan voor het internationale stroomgebiedsdistrict van de Maas. Luik, 22 december 2008. Internationale Maas Commissie (in Dutch).

Irvine, R.J., Kostakis, C., Felgate, P.D., Jaehne, E.J., Chen, C., White, J.M., 2011, Population drug use in Australia: A wastewater analysis, Forensic Sci. Int. 210, 69 - 73.

Jones-Lepp, T.L., Alvarez, D.A., Petty, J.D., Huckins, J.N., 2004, Polar organic chemical integrative sampling and liquid chromatography-electrospray/ion-trap mass spectrometry for assessing selected prescription and illicit drugs in treated sewage effluents, Arch. Environ. Contam. Toxicol. 47, 427 - 439.

Kasprzyk-Hordern, B., Dinsdale, R.M., Guwy, A.J., 2009. The removal of pharmaceuticals, personal care products, endocrine disruptors and illicit drugs during waste water treatment and its impact on the quality of receiving waters Water Res. 43, 363 - 380 
Kvanli, D.M., Marisetty, S., Anderson, T.A., Jackson, W.A., Morse, A.N., 2008, Monitoring Estrogen Compounds in Wastewater Recycling Systems. Water Air Soil Pollut. 188, 31 40.

Postigo, C., López de Alda, M., Barceló, D., 2010, Drugs of abuse and their metabolites in the Ebro river basin: Occurrence in sewage and surface water, sewage treatment plants removal efficiency, and collective drug usage estimation. Environ. Int. 36, 75 - 84.

SFK, 2008, Facts and figures. Foundation for pharmaceutical statistics. The Hague, The Netherlands.

Ter Laak, T., Van der Aa, M., Houtman, C., Stoks, P., Van Wezel, A., 2010, Relating environmental concentrations of pharmaceuticals to consumption: A mass balance approach for the river Rhine. Environ. Int. 36, 403 - 409.

Thomas, K.V., Bijlsma, L., Castiglioni, S., Covaci, A., Emke, E., Grabic, R., Hernandez, F., Karolak, S., Kasprzyk-Hordern, B., Lindberg, R.H., Lopez de Alda, M., Meierjohann, A., Ort, C., Pico, Y., Quintana, J.B., Reid, M., Rieckermann, J., Terzic, S., van Nuijs, A.L.N., de Voogt, P., 2012, Comparing illicit drug use in 19 European cities through sewage analysis. Sci. Total Environ. 432, 432 - 439.

Van Laar, M.W., Cruts, A.A.N., Verdurmen, J.E.E., Van Ooyen-Houben, M.J.J., Meijer, R.F., 2007, The Netherlands National Drug Monitor Annual Report 2006. Published by Trimbos Institute (Netherlands Institute of Mental Health and Addiction) AF0760, 1 219. Utrecht, The Netherlands.

van Nuijs, A.L.N., Pecceu, B., Theunis, L., Dubois, N., Charlier, C., Jorens, P.G., Bervoets, L., Blust, R., Neels, H., Covaci, A., 2009a, Spatial and temporal variations in the occurrence of cocaine and benzoylecgonine in waste- and surface water from Belgium and removal during wastewater treatment. Water Res. 43, 1341 - 1349. 
van Nuijs, A.L.N., Tarcomnicu, I., Bervoets, L., Blust, R., Jorens, P.G., Neels, H., Covaci, A., 2009b, Analysis of drugs of abuse in wastewater by hydrophilic interaction liquid chromatography-tandem mass spectrometry. Anal. Bioanal. Chem. 395, 819 - 828.

van Nuijs, A.L.N., Castiglioni, S., Tarcomnicu, I., Postigo, C., Lopez de Alba, M., Neels, H., Zuccato, E., Barcelo, D., Covaci, A., 2010, Illicit drug consumption estimations derived from wastewater analysis: a critical review. Sci. Total Environ. 409, 3564 - 3577.

Vanderford, B.J., Snyder, S.A., 2006, Analysis of pharmaceuticals in water by isotope dilution liquid chromatography/tandem mass spectrometry. Environ. Sci. Technol. 40, $7312-7320$.

539 Zuccato, E., Castiglioni, S., Bagnati, R., Chiabrando, C., Grassi, P., Fanelli, R., 2008a, Illicit 540 drugs, a novel group of environmental contaminants. Water Res. 42, 961 - 968.

541 Zuccato, E., Chiabrando, C., Castiglioni, S., Bagnati, R., Fanelli, R., 2008b. Estimating 542 community drug abuse by wastewater analysis. Environ. Health Perspect. 116, 1027 1032. 


\section{FIGURE CAPTION}

Figure 1. Estimated discharges (g/day) of DOA from STPs based on monitoring data and STP effluent flow rates in October 2009.

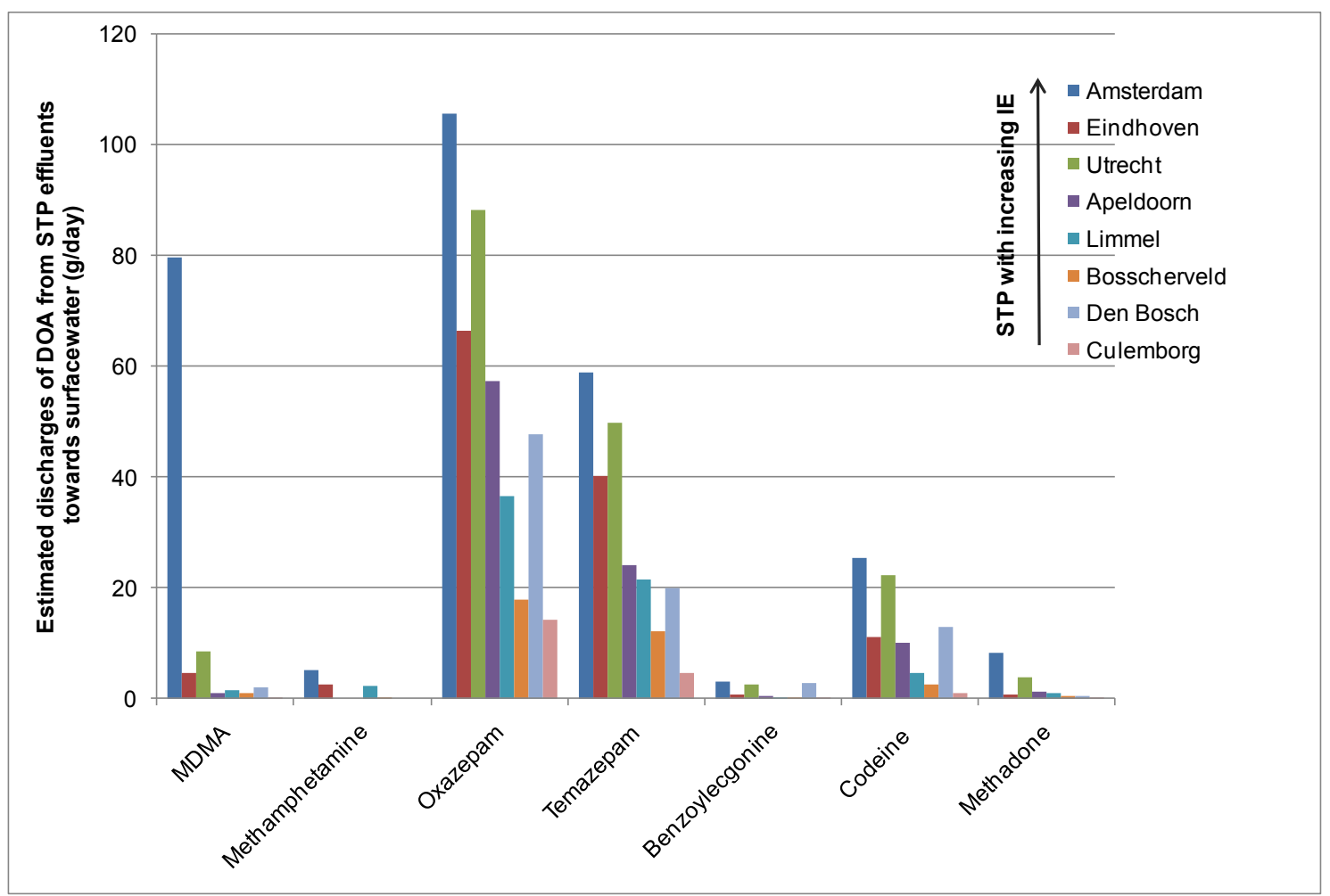




\section{FIGURE CAPTION}

Figure 2. Concentrations (ng/L) of DOA at border crossing locations (river Rhine: Lobith and river Meuse: Eijsden) and downstream (river Rhine at Maassluis and river Meuse at Keizersveer).

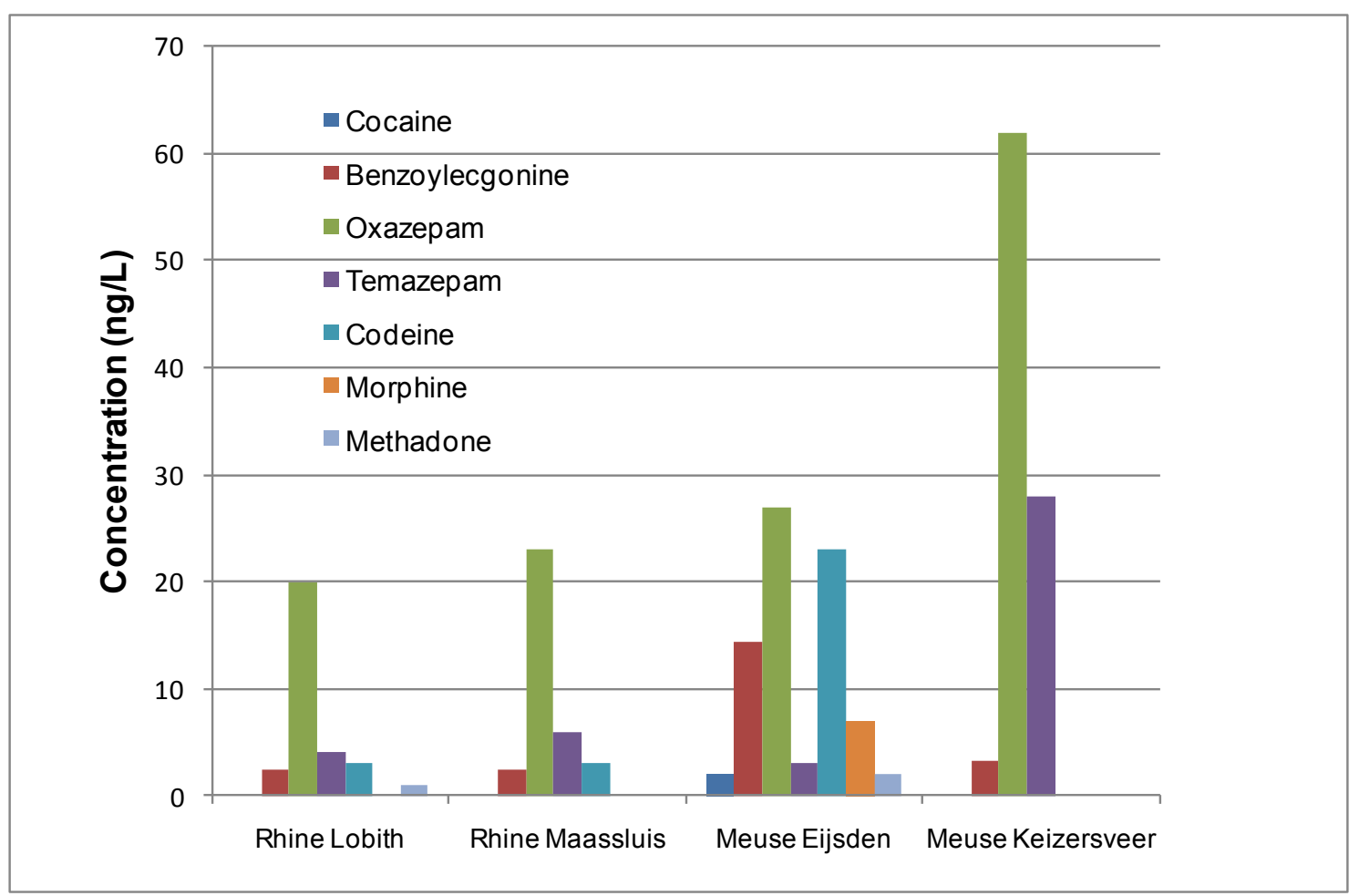




\section{FIGURE CAPTION}

Figure 3. Estimated loads (g/day) of DOA in rivers Rhine and Meuse at Dutch border crossing locations (Lobith and Eijsden, respectively) and downstream (Maassluis and Keizersveer, respectively) calculated from monitoring data and river flow rates on one sampling date in October 2009.

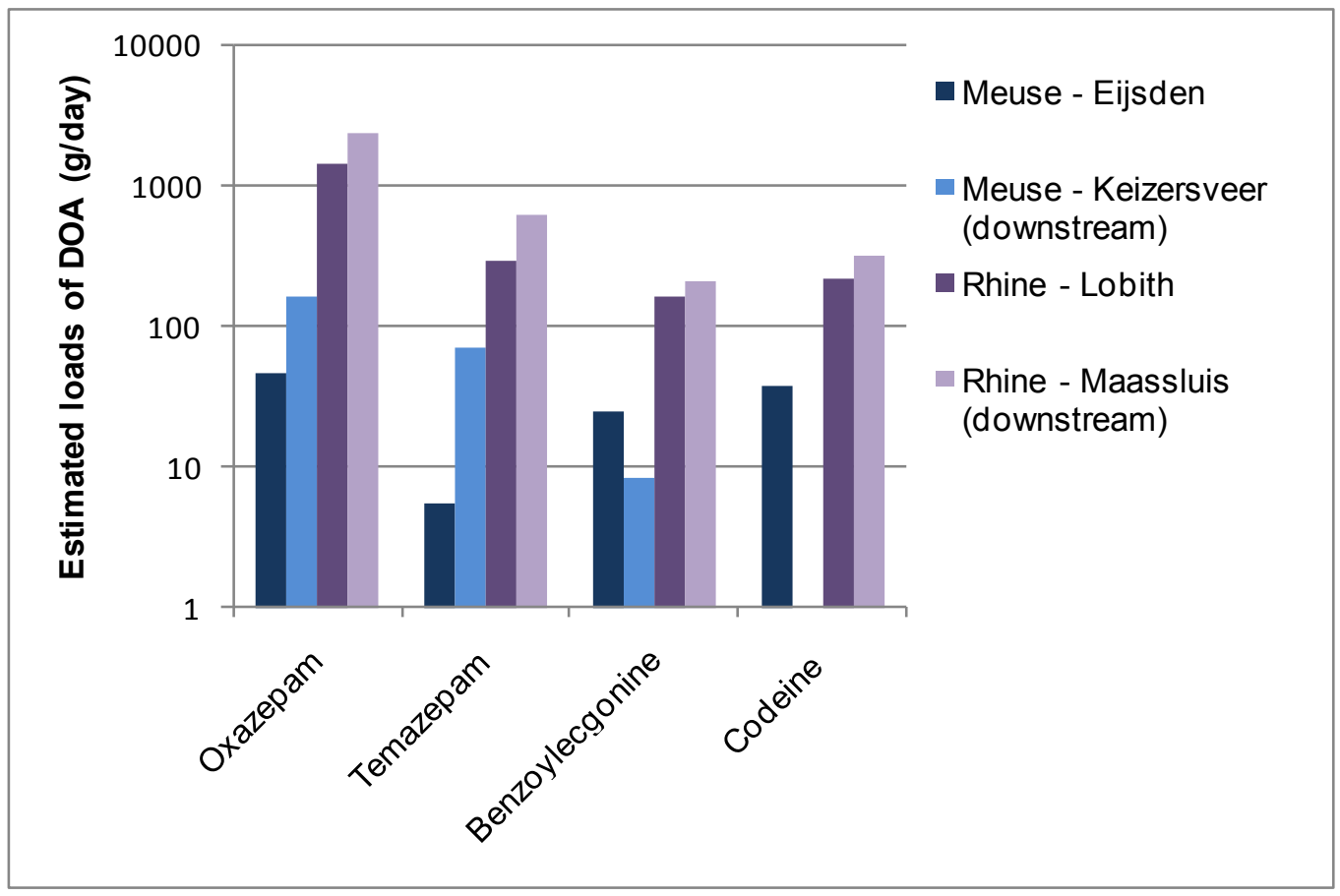




\section{FIGURE CAPTION}

Figure 4. Average concentrations $(\mathrm{ng} / \mathrm{L} \pm \mathrm{SD})$ of $\mathrm{DOA}$ in water collected from different stages of three types of drinking water production processes.

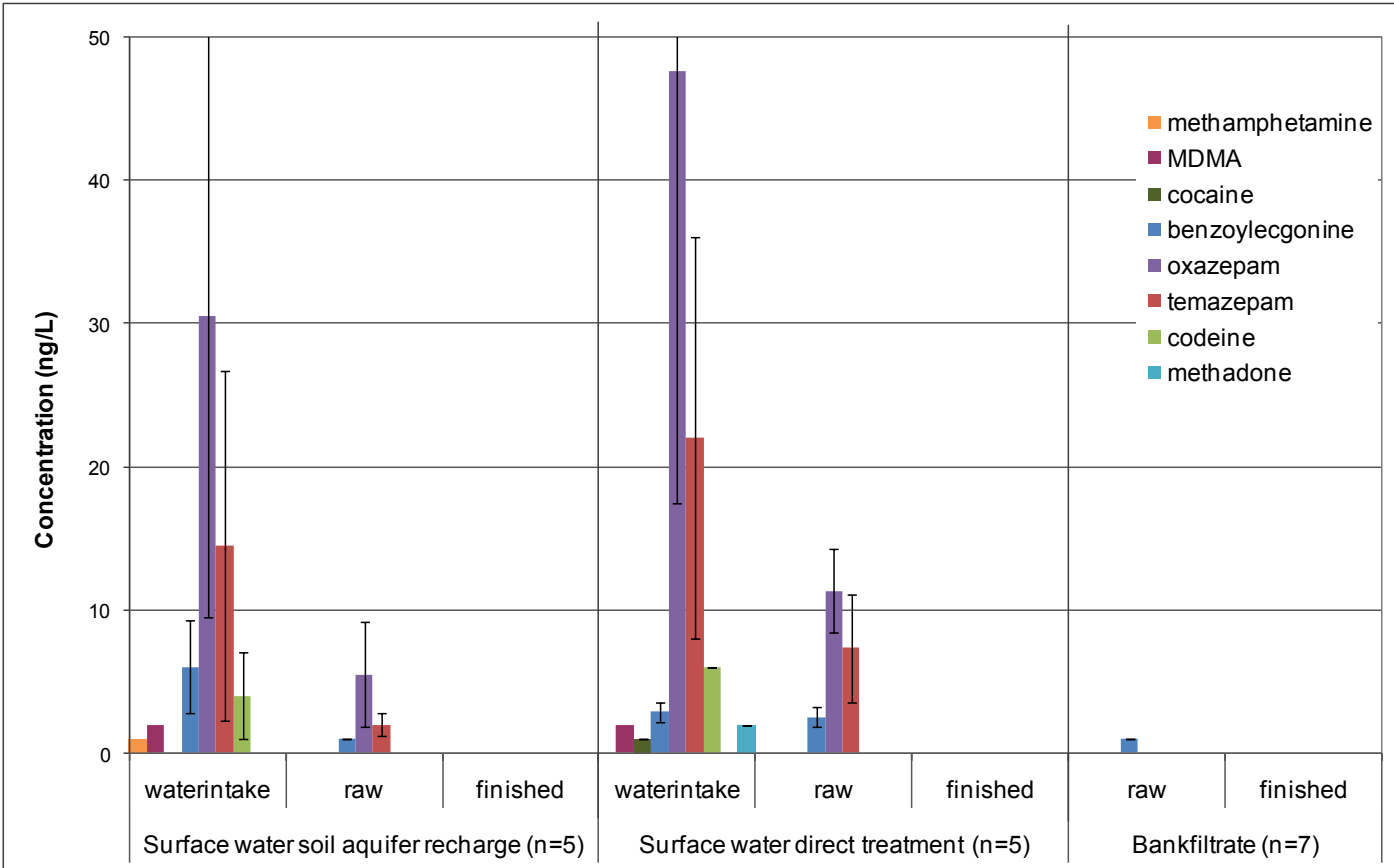


Table 1: Summary of the analytical methods used by the four laboratories

\begin{tabular}{|c|c|c|c|c|c|c|c|c|c|}
\hline & $\begin{array}{l}\text { Sample } \\
\text { volume }(\mathrm{mL}) \\
\end{array}$ & $\begin{array}{l}\text { Pre- } \\
\text { treatment }\end{array}$ & $\begin{array}{l}\mathrm{pH} \\
\text { adjustment }\end{array}$ & SPE column & $\begin{array}{l}\text { Type of analytical } \\
\text { LC column }\end{array}$ & $\begin{array}{l}\text { Final volume } \\
\text { extract }(\mu L)\end{array}$ & $\begin{array}{l}\text { Injection } \\
\text { volume }(\mu \mathrm{L})\end{array}$ & $\begin{array}{l}\text { Amount of sample } \\
\text { analysed }(\mathrm{mL})\end{array}$ & $\begin{array}{l}\text { Conc. } \\
\text { factors }\end{array}$ \\
\hline RIVM & 100 & none & No & Oasis HLB (6 cc, $200 \mathrm{mg})$ & $\mathrm{C}_{18}$ & 400 & 25 & 6.25 & 250 \\
\hline KWR & 900 & filtration & $\mathrm{pH} 7$ & Oasis HLB (6 cc, $150 \mathrm{mg})$ & $\mathrm{C}_{18}$ & 500 & 20 & 36 & 1800 \\
\hline UJI & 50 & $\begin{array}{l}\text { centri- } \\
\text { fugation }\end{array}$ & $\mathrm{pH} 2$ & Oasis MCX (6 cc, $150 \mathrm{mg})$ & $\mathrm{C}_{18}$ & 1000 & 20 & 1 & 50 \\
\hline UA & 50 & filtration & $\mathrm{pH} 2$ & Oasis MCX (3 cc, $60 \mathrm{mg})$ & HILIC & 200 & 5 & 1.25 & 250 \\
\hline
\end{tabular}


1 Table 2: Occurrence of DOA and metabolites in Dutch waters (levels quantified (average \pm standard deviation (SD), range and median))

\begin{tabular}{|c|c|c|c|c|c|c|c|c|c|c|c|c|c|c|c|c|}
\hline & \multicolumn{4}{|c|}{ Influent sewage water } & \multicolumn{4}{|c|}{ Effluent sewage water } & \multicolumn{4}{|c|}{ Surface water } & \multicolumn{4}{|c|}{ Raw drinking- / process water } \\
\hline & \multirow[b]{2}{*}{$\mathrm{FD}^{\mathrm{a}}$} & \multicolumn{3}{|c|}{ Concentration (ng/L) } & \multirow[b]{2}{*}{$\mathrm{FD}^{\mathrm{a}}$} & \multicolumn{3}{|c|}{ Concentration (ng/L) } & \multirow[b]{2}{*}{$\mathrm{FD}^{\mathrm{a}}$} & \multicolumn{3}{|c|}{ Concentration $(\mathrm{ng} / \mathrm{L})$} & \multirow[b]{2}{*}{$\mathrm{FD}^{\mathrm{a}}$} & \multicolumn{3}{|c|}{ Concentration (ng/L) } \\
\hline & & $\begin{array}{c}\text { Average } \pm \\
\text { SD }\end{array}$ & Range & Median & & $\begin{array}{c}\text { Average } \pm \\
\text { SD }\end{array}$ & Range & Median & & $\begin{array}{l}\text { Average } \pm \\
\text { SD }\end{array}$ & Range & Median & & $\begin{array}{c}\text { Average } \pm \\
\text { SD }\end{array}$ & Range & Median \\
\hline Amphetamine & $8 / 8$ & $334 \pm 179$ & $107-581$ & 310 & $1 / 8$ & 15 & & & & & & & & & & \\
\hline Methamphetamine & $2 / 8$ & $151 \pm 180$ & $24-278$ & 151 & $4 / 8$ & $37 \pm 20$ & $13-62$ & 33 & $1 / 14$ & 1 & & & & & & \\
\hline MDA & & & & & $1 / 8$ & 22 & & & & & & & & & & \\
\hline MDMA & $8 / 8$ & $109 \pm 51$ & $42-207$ & 102 & $8 / 8$ & $126 \pm 174$ & $17-537$ & 56 & $4 / 14$ & $2 \pm 1$ & $1-2$ & 2 & & & & \\
\hline Diazepam & & & & & $5 / 8$ & $4 \pm 1$ & $2-5$ & 3 & & & & & & & & \\
\hline Nordazepam & & & & & $5 / 8$ & $19 \pm 7$ & $13-31$ & 18 & & & & & & & & \\
\hline Oxazepam & $8 / 8$ & $1167 \pm 445$ & $602-2020$ & 1105 & $8 / 8$ & $1122 \pm 375$ & $713-1746$ & 959 & $12 / 14$ & $29 \pm 22$ & $6-68$ & 25 & $7 / 17$ & $8 \pm 5$ & $3-13$ & 8 \\
\hline Temazepam & $8 / 8$ & $427 \pm 179$ & $255-813$ & 411 & $8 / 8$ & $568 \pm 198$ & $389-1016$ & 554 & $12 / 14$ & $12 \pm 12$ & $3-32$ & 6 & $7 / 17$ & $4 \pm 4$ & $1-10$ & 3 \\
\hline THC-COOH & $7 / 8$ & $424 \pm 137$ & $289-678$ & 378 & & & & & & & & & & & & \\
\hline Cocaine & $8 / 8$ & $438 \pm 245$ & $135-904$ & 363 & $6 / 8$ & $4 \pm 3$ & $1-11$ & 3 & $2 / 14$ & $2 \pm 1$ & $1-3$ & 2 & & & & \\
\hline Benzoylecgonine & $8 / 8$ & $1703 \pm 870$ & $570-2907$ & 1463 & $8 / 8$ & $26 \pm 25$ & $7-84$ & 20 & $10 / 14$ & $5 \pm 4$ & $1-16$ & 3 & $5 / 17$ & $2 \pm 1$ & $1-3$ & 1 \\
\hline Cocaethylene & $7 / 8$ & $27 \pm 19$ & $8-62$ & 19 & & & & & & & & & & & & \\
\hline Norbenzoylecgonine & $6 / 8$ & $36 \pm 16$ & $18-60$ & 38 & $4 / 8$ & $4 \pm 1$ & $3-5$ & 4 & & & & & & & & \\
\hline Norcocaine & $6 / 8$ & $20 \pm 10$ & $10-39$ & 17 & $1 / 8$ & 4 & & & & & & & & & & \\
\hline Ecgonine methylester & $4 / 4^{b}$ & $207 \pm 97$ & $84-312$ & 216 & $3 / 4^{\mathrm{b}}$ & $41 \pm 2$ & $3-6$ & 3 & & & & & & & & \\
\hline 6-MAM & $1 / 8$ & 3 & & & $2 / 8$ & $5 \pm 2$ & $3-6$ & 5 & & & & & & & & \\
\hline Morphine & $8 / 8$ & $665 \pm 418$ & $300-1464$ & 517 & $7 / 8$ & $31 \pm 22$ & $7-68$ & 20 & $1 / 14$ & 7 & & & & & & \\
\hline Codeine & $8 / 8$ & $580 \pm 230$ & $300-975$ & 526 & $8 / 8$ & $192 \pm 88$ & $110-378$ & 168 & $7 / 14$ & $7 \pm 8$ & $1-23$ & 4 & & & & \\
\hline Methadone & $4 / 8$ & $37 \pm 20$ & $16-64$ & 34 & $8 / 8$ & $29 \pm 19$ & $6-56$ & 22 & $3 / 14$ & $2 \pm 1$ & $1-2$ & 2 & & & & \\
\hline EDDP & $4 / 4^{\mathrm{b}}$ & $84 \pm 41$ & $36-135$ & 82 & $4 / 4^{\mathrm{b}}$ & $73 \pm 43$ & $25-128$ & 67 & & & & & & & & \\
\hline Fentanyl & & & & & $1 / 8$ & 8 & & & & & & & & & & \\
\hline Ketamine & & & & & $6 / 8$ & $16 \pm 12$ & $2-28$ & 10 & & & & & & & & \\
\hline Methcathinone & & & & & $1 / 8$ & 4 & & & & & & & & & & \\
\hline Ritalin & & & & & $6 / 8$ & $5 \pm 3$ & $2-9$ & 6 & & & & & & & & \\
\hline
\end{tabular}

$2 \quad$ : Frequency of determination

3 b: Analyzed by UA (STPs: Utrecht, Apeldoorn, Amsterdam, Eindhoven) 
Table 3: Environmental Risk Characterization Ratios for eight ${ }^{\mathrm{a}}$ drugs of abuse

\begin{tabular}{|c|c|c|c|c|}
\hline Substance & PNEC $(\mu \mathrm{g} / \mathrm{L})$ & $\begin{array}{l}\text { Max. conc. }(\mu \mathrm{g} / \mathrm{L}) \text { in } \\
\text { surface water }(\mathrm{MEC})\end{array}$ & $\begin{array}{c}\text { Environmental Risk Characte } \\
\text { ratio (MEC/PNEC) }\end{array}$ & on \\
\hline Methamphetamine & $2.30^{\mathrm{b}}$ & 0.001 & 0.0004 & 4 \\
\hline MDMA & $2.70^{\mathrm{b}}$ & 0.002 & 0.0007 & 5 \\
\hline Oxazepam & 4.30 & 0.068 & \multirow{2}{*}{$\Sigma 0.0234^{\mathrm{d}}$} & 6 \\
\hline Temazepam & $4.30^{\mathrm{c}}$ & 0.032 & & 0 \\
\hline Cocaine & $4.90^{\mathrm{b}}$ & 0.003 & 0.0006 & 7 \\
\hline Benzoylecgonine & $4.90^{\mathrm{c}}$ & 0.016 & 0.0033 & 8 \\
\hline Morphine & $32.0^{\mathrm{b}}$ & 0.007 & 0.0002 & 9 \\
\hline Codeine & $0.06^{\mathrm{b}}$ & 0.023 & 0.3800 & 10 \\
\hline
\end{tabular}

11 a For methadone, which was also detected in surface water (Table 2), no PNEC could be found.

$12{ }^{\mathrm{b}}$ PNEC $_{(\mathrm{ECOSAR})}$, ECOlogical Structure Activity Relationships (ECOSAR) models are used to estimate PNEC.

$13^{\mathrm{c}}$ default PNEC, set at the same level as a related compound with similar metabolic pathway.

14 d sum of oxazepam and temazepam 